\title{
Left-right asymmetry in two types of soccer kick
}

\author{
B. D. McLean PhD and D. McA. Tumilty MPE \\ Australian Institute of Sport, Belconnen, Australia
}

\begin{abstract}
The ability to kick with both feet is regarded as a desirable skill in high level soccer players; however, most players display a dominance of kicking ability on one side. This study investigated the characteristics of asymmetry in two types of soccer kick. A low drive and a chip kick from both the left and right foot of $\mathbf{1 2}$ élite junior soccer players were analysed. Kick velocity, kick accuracy, position of the plant foot from the ball centre, and time from foot plant to ball contact were measured for each kick. Knee extension and flexion strength were also determined for each leg at $60^{\circ} \mathrm{s}^{-1}, 180^{\circ} \mathrm{s}^{-1}$ and $240^{\circ} \mathrm{s}^{-1}$ on a Cybex II Isokinetic Dynamometer. A single factor repeated measures analysis of variance was applied to velocity, plant foot position and timing parameters to compare between sides and between shots. $\chi^{2}$ analysis was used to compare accuracy between shots and between sides, and a paired Student's $t$ test was used to compare strength parameters between sides. Pearson's product moment correlation analysis was used to examine the relationship between velocity and both leg strength and the time from foot plant to ball contact. Significance was set at $P \leq 0.05$. The results showed that this group had strength dominance at all speeds tested on the right side and better drive kick performance with their right leg as determined by mean(s.d.) velocity $(79(6)$ versus $\left.66(8) \mathrm{km} \mathrm{h}^{-1}\right)$ and accuracy $(66.6 \%$ versus $33.3 \%)$. There was no difference in these parameters between sides for chip kicks. When kicking with the right leg the mean(s.d.) distance of the plant foot to the centre of the ball was less for both drive $(386(28)$ versus $462(31) \mathrm{mm})$ and chip kicks (369(35) versus $458(25) \mathrm{mm}$ ). In addition, time from foot plant to ball contact did not differ between the sides for either type of kick and no relationship was found between this time parameter and kick velocity except for the right foot drive $(r=-0.57)$. No relationship was found between strength and kick velocity for either kick.
\end{abstract}

Keywords: Kicking performance, asymmetry

Starosta ${ }^{1}$, in an extensive analysis of shots at goal during World Cup and other high level competitions, showed that the most successful players shot for goal with both left and right feet. He concluded that development of symmetry in shooting should form part of the preparation of the soccer player. However, little has been reported on asymmetry of kicking performance and the parameters that characterize it. The aim of this study was to investigate asymmetry in the characteristics of two types of soccer kick.

Address for correspondence: Dr B. D. McLean, Australian Institute of Sport, PO Box 176, Belconnen, ACT, 2616, Australia

(C) 1993 Butterworth-Heinemann Ltd

0306-3674/93/040260-03

\section{Subjects and methods}

Twelve élite Australian junior soccer players who were scholarship holders of the Junior Development Squad at the Australian Institute of Sport served as subjects in this study. Anthropometric details are shown in Table 1.

The playing positions occupied by these players were: one fullback, four midfielders, two strikers, two midfield/strikers and three centre/defenders. Only one player was considered by the coach to be naturally left footed. The others were considered to be right sided kickers. Subjects presented for testing on one of two consecutive afternoons with the coach present. Each was instructed on the types of kicks to perform and was given a demonstration by the coach. Subjects were then given time to warm up by practise kicking.

Each subject attempted a low drive kick and a chip kick with both left and right foot. Two attempts were made at each shot for each foot. For the drive, subjects attempted to kick the ball low and at high velocity between flags $20 \mathrm{~m}$ apart and at $35 \mathrm{~m}$ from the ball. A kick was successful if it passed between the flags. The chip kick involved attempting to lift the ball over flags set at $20 \mathrm{~m}$ from the kick position and having it come down before the $35 \mathrm{~m}$ flags. Landing the ball within the space bounded by the four flags was considered a successful kick. All kicks were made from an artificial Rekortan (Voigt Sohne Gmbh, Castrop-Rauxel, Germany) surface with a three step approach. The velocity of each kick was measured by a Midex radar gun (Mountain View, California, USA).

Position of the plant foot relative to the centre of the ball was determined by digitizing a video image taken from an overhead view. The position of the foot was taken as that point at one-third of the distance from the heel to the toe. Total distance from this point to the centre of the ball, as well as the components of this distance, to the side of the ball and fore and aft distance, were also determined.

Time from foot plant to ball contact was calculated from first contact on a Kistler force plate $(\mathrm{Z} 4852 / \mathrm{C})$ (Winter-thur, Switzerland) until a microphone trigger

Table 1. Subject details

\begin{tabular}{lr}
\hline Age (years) & $16.8(0.7)$ \\
Weight $(\mathrm{kg})$ & $70.3(4.8)$ \\
Height $(\mathrm{cm})$ & $176.1(7.1)$
\end{tabular}

Values are mean(s.d.) 
adjacent to the ball was set off by ball contact. Two trials were allowed for each shot and values averaged before statistical analysis. For the analysis of kicking accuracy each trial was included, giving a frequency of successful kicks out of a possible total of 24 .

Isokinetic knee flexion and extension strength was measured on a Cybex II Isokinetic Dynamometer (Cybex, Ronkonkoma, New York, USA). Testing was conducted in the week before the kick tests. These tests formed part of the subject's routine physiological testing battery to which they were frequently exposed. Before testing, each subject warmed up by pedalling on a cycle ergometer. The subject was then seated on the apparatus and restraining straps placed around the chest, hips and thigh. The torque arm was adjusted so that the ankle pad could be secured just above the medial malleolus. The limb was then placed in the fully extended position and the subject asked to relax. The speed was increased to allow the relaxed limb to fall under the weight of gravity. The maximum registered torque was considered as the gravity correction and added to extension readings and subtracted from flexion readings. Several submaximal warm up repetitions were performed at $60^{\circ} \mathrm{s}^{-1}$ until the subject was familiar with the action of the dynamometer. The warm up was concluded by the subject performing one maximal repetition. The subject then performed three maximal effort extensions and flexions of the knee at $60^{\circ} \mathrm{s}^{-1}$, the highest value being recorded. A 1-min rest was allowed before the subject repeated the procedure at $180^{\circ} \mathrm{s}^{-1}$ and at $240^{\circ} \mathrm{s}^{-1}$.

Comparison of velocity, foot placement and timing parameters between sides and between shots was conducted by a one-factor repeated measures analysis of variance. Significant F ratios were followed by Scheffes post-hoc analysis. Comparison of knee extension and flexion strength between the left and right leg was carried out by a paired Students' $t$ test and the relationship between kick velocity and both strength parameters and the time from foot placement to ball contact was examined by Pearson's product moment correlation analysis. Analysis of shot accuracy between sides and between shots was conducted by a $\chi^{2}$ analysis. For all statistical tests, type I error rate was fixed at 0.05 .

\section{Results}

Mean values of ball velocity, foot placement parameters, kicking accuracy and the time from foot plant to ball contact for each shot are presented in Table 2. These results show that this group had better drive kick performance with their right leg as determined by drive velocity and accuracy, and had greater knee extension and flexion strength on the right side (Table 3). Chip kicks, however, did not show any differences in these parameters between left and right sides.

The total distance of the plant foot from the centre of the ball was smaller for both drive and chip right side kicks than those on the left. When this total distance was broken into the components to the side of the ball and forward or rear of the ball centre, there was a smaller distance to the side of the ball for right
Table 2. Velocity, accuracy, foot placement and timing parameters for left and right side drive and chip kicks

\begin{tabular}{|c|c|c|c|c|}
\hline & Right drive & Right chip & Left drive & Left chip \\
\hline $\begin{array}{l}\text { Velocity }\left(\mathrm{km} \mathrm{h}^{-1}\right) \\
\text { Accuracy (frequency) }\end{array}$ & $\begin{array}{l}79(6)^{*} \dagger \\
16 \text { of } 24^{*}\end{array}$ & $\begin{array}{l}66(5)^{*} \\
14 \text { of } 24\end{array}$ & $\begin{array}{l}66(8) \dagger \\
8 \text { of } 24^{*}\end{array}$ & $\begin{array}{l}64(5) \\
12 \text { of } 24\end{array}$ \\
\hline $\begin{array}{l}\text { Total distance of } \\
\text { plant foot from } \\
\text { ball }(\mathrm{mm})\end{array}$ & $386(28)^{*}$ & $369(35) \dagger$ & $462(31)^{*}$ & $458(25) \dagger$ \\
\hline $\begin{array}{l}\text { Distance of plant foot } \\
\text { at side of ball }(\mathrm{mm})\end{array}$ & $373(41)^{*}$ & $357(34) \dagger$ & $451(32)^{*}$ & $451(20) \dagger$ \\
\hline $\begin{array}{c}\text { Distance of plant foot } \\
\text { behind ball }(\mathrm{mm})\end{array}$ & $81(53)$ & $71(57)$ & $39(91)$ & $34(80)$ \\
\hline $\begin{array}{l}\text { Time from foot plant } \\
\text { to ball contact }(\mathrm{ms})\end{array}$ & $120(8)^{*}$ & $128(8)^{*}$ & 121(9) & $127(9)$ \\
\hline
\end{tabular}

Values are mean(s.d); ${ }^{*}$ tvalues indicated with the same symbol are significantly different, $P<0.05$, one-factor repeated measures analysis of variance in conjunction with Scheffes post-hoc comparisons

Table 3. Isokinetic knee flexion and extension strength

\begin{tabular}{lcc}
\hline & Right limb & Left limb \\
\hline Extension $60^{\circ} \mathrm{s}^{-1}(\mathrm{~N} \mathrm{~m})$ & $239(28)$ & $218(29)^{*}$ \\
Flexion $60^{\circ} \mathrm{s}^{-1}(\mathrm{~N} \mathrm{~m})$ & $120(22)$ & $111(18)$ \\
Extension $180^{\circ} \mathrm{s}^{-1}(\mathrm{~N} \mathrm{~m})$ & $153(24)$ & $137(20)^{*}$ \\
Flexion $180^{\circ} \mathrm{s}^{-1}(\mathrm{~N} \mathrm{~m})$ & $87(17)$ & $84(13)$ \\
Extension $240^{\circ} \mathrm{s}^{-1}(\mathrm{~N} \mathrm{~m})$ & $129(19)$ & $117(18)^{*}$ \\
Flexion $240^{\circ} \mathrm{s}^{-1}(\mathrm{~N} \mathrm{~m})$ & $73(14)$ & $74(9)$ \\
\hline
\end{tabular}

Values are mean(s.d.); *significantly different to the corresponding value for the right $\operatorname{limb} P<0.05$, Student's paired $t$ test

foot kicks. This was the case for both drive and chip kicks. However, there was no significant difference in distance forward of the ball for either type of kick. Similarly time from foot plant to ball contact on left and right side was not different for either drive or chip kick.

Comparison of the drive and chip kicks showed that the right side drive velocity was higher than chip velocity, but that there was no difference between drive and chip velocity on the left side. Further, drive and chip kick accuracies were not different on either left or right sides. However, time from foot plant to ball contact was shorter for the drive than for the chip kick on the right side and showed the same non-significant trend on the left.

Placement of the plant foot from the ball was similar for both drive and chip kicks when considered on each side even though there was a difference in these parameters between sides. Correlation analysis showed no significant relationship between strength of knee flexion and extension and drive or chip velocity for either left or right leg. In addition no relationship was seen between time from foot placement to ball strike and ball velocity except for the right foot drive $(r=-0.57)$.

\section{Discussion}

These soccer players demonstrated lower limb strength dominance on the right side and showed a better drive kick performance with this limb. How- 
ever, chip kick velocity and accuracy did not show this trend. The chip kick that these athletes were asked to perform placed more emphasis on skill and less on power than the drive shot, and this may account for the similarity in chip velocity between the sides, as well as a higher drive velocity than chip velocity on the right side. Chip kick accuracy was $50 \%$ on the left side and only slightly better on the right, showing that this task was difficult on both sides for players at this level of skill.

The difference in execution between the shots was further highlighted by the trend towards a longer time from foot plant to ball contact in chip compared with drive kicks. This is consistent with a higher drive velocity than chip velocity as seen on the right side. However, the velocity between shots was similar on the left side, which suggests that other factors besides velocity of the kicking limb contribute to final ball velocity. Correlation analysis supports this view as only the time from foot contact to ball strike on the right foot drive showed a significant relationship with ball velocity.

In addition, no significant relationship was seen between isokinetic knee strength parameters and ball velocity for any kick. This is in contrast to previously reported findings that have shown a high correlation of between 0.74 and 0.82 for these parameters ${ }^{2,3}$. The inconsistency between the present findings and these earlier studies may be due to the differences in the task evaluated. In these previous studies maximum drive velocity was assessed with no requirement for accuracy. In the present study the added requirement of accuracy may have inhibited the effort that could be applied to kicking the ball with maximum power.

The finding that the plant foot was further to the side of the ball when making left foot kicks than when making right foot kicks may be related to the lower strength and skill on that side. Plagenhoef ${ }^{4}$ demonstrated that the correct sequencing of the acceleration and deceleration of the lower limb segments is necessary to achieve maximum foot velocity. If the neuromuscular coordination to achieve this is not high, other mechanisms may be used to increase foot velocity. Placing the plant foot further from the ball provides the opportunity for the kicking foot to sweep out a greater arc from the finish of its backswing until contact with the ball. A longer foot swing will allow force to be applied over a greater distance, giving more time to accelerate the limb. This strategy may be adopted to overcome the strength and skill deficit in the left leg.

This study has identified some of the characteristics of asymmetry in soccer kicking performance. Strength and kicking technique differences between sides have been shown. However, the relationships between these parameters and kicking performance has not been fully investigated. Further study is required to determine how these parameters influence kicking performance.

\section{References}

1 Starosta W. Symmetry and asymmetry in shooting demonstrated by elite soccer players. In: Reilly $T$, Lees A, Davids $K$, Murphy W, eds. Science and Football. London, UK: E. and F. N. Spon, 1988: 346-55.

2 Narici MV, Sirtori M, Mognoni P. Maximum ball velocity and peak torques of hip flexor and knee extensor muscles. In: Reilly T, Lees A, Davids K, Murphy W, eds. Science and Football. London, UK: E. and F. N. Spon, 1988: 429-33.

3 Cabri J, De Proft E, Dufour W, Clarys JP. The relation between muscular strength and kick performance. In: Reilly T, Lees A, Davids K, Murphy W, eds. Science and Football. London, UK: E. and F. N. Spon, 1988: 186-93.

4 Plagenhoef S. Patterns of Human Motion. A Cinematographic Analysis. Englewood Cliffs, New Jersey, USA: Prentice-Hall, 1971 . 